chiatric thought, and because their regulation by the DHSS owes more to political expediency than it does to medical wisdom. They must be unshackled from direct Governmental control and brought under the management of a specially constituted health authority. Its first task must be the re-defining of function in a form that is clinically realistic. Their national catchment areas must be sectorized so that units within each of the Special Hospitals can integrate with the various local secure facilities for mentally abnormal ofienders which are slowly developing. Finally, it must be acknowledged that an institution does not automatically become a hospital because the sign over the door says so.

REPBRENCES

'MACCuULOCH, M. J. (1977) Some problems of placing psychiatric patients. Health Trends, 9, 59-62.

2Genens, T. C. N., SOOtrmL, K. L. \& Pope, P. J. (1977) Medical Remands in the Criminal Court. Maudsley Monograph No. 25. Oxford University Press.

'WALSE-Brennan, K. S. (1978) Classification inconsistencies in defining the criminally mentally abnormal. Medictne, Science and the Law,18, 283-86.

'EDTrorinl (1977) Inhumanity to man. British Medical Journal, ii, 591-92.

'Bzown, C. T. (1973) Assessment of Regional Differences in Rates of Referral for Special Hospital Placement: Special Hospitals Research Report No. 7. London: Special Hospitals Research Unit.
GGrennand, C. (1970) The three Special Hospitals in England and patients with dangerous, violent or criminal propensities. Medicine, Science and the Law, 10, 93-103.

'MACPHAII, D. S. \& CoX, M. (1975) Dynamic peychotherapy with dangerous patients. Psychotherapy and Psychosomatics, 25, 13-19.

'DzLL, S. (1980) Transfer of Special Hospital patients to the NHS. British Jourmal of Psychiatry, 136, 222-34.

-Departmient of hibalth and Social Securaty, home Oppice, Wrlsh Opfice, lord Chancellor's Dzpartmignt (1981) Reform of Mental Health Legislation. Cmnd. 8405. London: HMSO.

${ }^{10}$ StAH, S. A. (1975) Dangerousness and civil commitment of the mentally ill: Some public policy considerations. American Journal of Psychiatry, 132, 501-55.

"VAUGhan, P. J. (1980) Letters and visits to long-stay Broadmoor patients. British Journal of Social Work, 10, 471-81.

'BRLCH, S. \& ReDDAwAy, P. (1977) Russia's Political Hospitals. London: Gollancz.

${ }^{13}$ EstmutBs ComantrBB (1968) Second Report from the Estimates Committee: the Spectal Hospitals and the State Hospital. London: HMSO.

${ }^{14}$ Scottish Home aND Hralth Dapartugent (1977) State Hospital, Carstairs: Report of Public Local Inquiry into Circumstances Surrounding the Escape of Two Pattents on 30 November 1976 and into Security and Other Arrangements at the Hospital. Edinburgh: HMSO.

${ }^{13}$ DEPARTMENT OP HEalth AND SOCIAl SEcurtTy (1980) Report of the Review of Rampion Hospital. Cmnd. 8073. London: HMSO.

The views presented in this paper are those of the author and do not necessarily reflect those of the Scottish Home and Health Department.

\title{
Trials of An Approval Team Convener
}

PAul K. Bridges, Physician in Psychological Medicine and Senior Lecturer, Guy's Hospital Medical School, London

I have been a member of the Southern Division Approval Panel since its inception in 1972. Thereafter I visited, with other panel members, two or three hospitals per year. I became Convener in 1978 and in my four years in office I visited over 35 hospitals, although these were not all separate visits. I look after a catchment area in South-East London, with all the in-patient services at Bexley Hospital. It is entirely my personal opinion that if I was not involved with a district service I probably would not have accepted the invitation to be a convener. I do not think I would necessarily have been a worse convener, but I might have been rather less credible.

There have been occasionally muted remarks on visits about 'those from ivory towers', although this has referred to the South-East of England as often as it has been intended to refer to London Teaching Hospitals. Interestingly, it has been the unanimous view of all my colleagues from the south who have joined me on visits to northern hospitals, that as regards fabric and general decoration, psychiatric hospitals in the north are perceptibly superior to those in the south. Can it be that RAWP is succeeding? Equally, the quality of trainees, especially around major teaching centres in the north has usually been as good and better than that of those in most psychiatric hospitals around southern London.

As the Approval visits developed, it was very satisfying to see training programmes improving, and rotations being slowly built up, offering wider experience to junior doctors, often together with more effective teaching opportunities for consultants. Obviously, these developments were not specifically brought about by any special excellence shown by the Southern Division Approval Panel. Rather, they are signs of the general success of the Approval Exercise.

Communication, both to and from the hospitals visited, was of crucial importance. Also very important was the general dissemination of ideas from the various rotating members on the visiting team. In addition, the Convener will 
know what is happening in other hospitals within the Division that he has previously visited, and he will be able to bring to bear on the visit his experiences of the consensus views at the Central Panel meetings.

The Central Panel consists of all the Conveners and consensus views are the aim, derived from the opinions of the members, who will also have local information involving virtually the entire College. In this way, with the guidance of the Dean, the Central Panel comes to a general view as to what types of training and clinical experience should be encouraged and how much should be expected of hospitals despite quite widely differing circumstances. It is this wideranging view of appropriate training that the Convener will have in mind when visiting. Occasionally, conveners may have a few bright, but perhaps unrealistic ideas of their own, but these are usually modified by other members of the visiting team.

The Central Panel meets three or four times each year and discusses the reports presented by conveners who have recently visited hospitals. The individual team's recommendation may be accepted by the Central Panel to be forwarded to the Court of Electors, but the Panel sometimes reverses the recommendation of a visiting team. The Court of Electors has the final authority to accept or modify the recommended Approval category. So the Court may, and sometimes does, reject a recommendation made by an Approval team and approved by the Central Panel. When a team's suggested recommendation is not accepted by the Panel or the Court, there may be confusion and irritation caused to the clinical tutor and consultants at the hospital involved. They should, of course, have been warned of this possibility, and that the recommendations are solely those of the visiting team, when they are discussed at the end of the visit. The Court of Electors encourages the visiting team to present their recommendations to the hospital visited, none the less.

One thing is made clear from Approval visits. The considerable majority of consultants are very keen to teach and the possibility of their hospital being unapproved, and therefore having no trainees, causes much real concern. It is frequently stressed that the presence of trainees improves all aspects of a psychiatric service, and teaching keeps consultants intellectually stimulated and more effectively involved in their clinical work. Indeed, consultants will usually tolerate a good deal of inconvenience and will make considerable efforts to ensure that their hospital has a satisfactory training programme. Therefore some degree of confrontation can occur between the visiting team and the senior medical staff of the hospital being visited, as feelings may run high.

Of course the Approval Exercise is all about training and trainees. The junior doctors may be seen individually by the visiting panel, and are specifically invited to do so if they prefer. But often there are too many trainees so they are seen in small groups or all together and the trainees often opt for this. At one particularly effective meeting, the trainees had met previously and they drew up an agenda for the meeting with the panel. Not surprisingly, the main information about the training available comes from the junior doctors. One can readily discover whether trainees have actually seen a mentally handicapped patient and whether there are in reality regular case conferences. Sometimes a major deficiency in the teaching by a particular senior doctor comes to light and this situation requires an immense amount of tact to deal with.

Perusal of the case notes, especially of longer stay patients, gives useful information about the supervision of junior doctors and about patient care. Of course, the notes on the progress of trainees kept by the clinical tutor are always inspected. Good training requires reasonable environmental comfort, so the library is inspected for its furniture and quiet as well as for its books. The duty doctors' accommodation can be revealing of the hospital's interest in its trainees. One team I was on achieved a minor victory by getting the duty doctor's bed, broken for six months, replaced in hours.

This laudable self-pride, which so many consultants experience in their teaching of junior doctors, tends to be associated with a widespread misunderstanding as to the purpose of the Approval Exercise. The aim, of course, is to bring all psychiatric training throughout Britain at least up to an acceptable minimum level. If training is inadequate, there can be imposed a threat of a change to the Unapproved category if the deficiencies are not remedied. Many clinical tutors and their consultant colleagues unfortunately tend to feel that even the Provisional Approval category implies failure, even sometimes being seen as blame involving them personally. However, there are many reasons for a hospital not coming up to full Approval standard for its postgraduate education. Sometimes there is excellent consultant teaching but inadequate awareness of the need, nowadays, for varied training programmes with good subspecialty experience, as well as case conferences, seminars and journal clubs. Furthermore, a hospital may believe that its training programme is excellent-and so it may be, up to a pointbut be unaware that similar hospitals are achieving more effective training by an up-dated programme.

A few hospitals are unaware of the quite considerable time-off recommended by the DHSS for the education of junior doctors. This involves a basic allowance of study leave of two half-days a week for 30 weeks of the year together with regular educational activities of three hours a week for $\mathbf{3 0}$ weeks of the academic year. There may be too few consultants to adequately supervise the trainees or their clinical load generally may be excessive. Sometimes, there may be no MRCPsych course within a reasonable travelling distance for day-release education, or the library and other postgraduate facilities may be poor. The trainee-rotation may be under-developed, so that junior doctors spend too long in one clinical setting, although consultants tend to 
prefer their juniors to be with them for longer than the sixmonth placements, which seem best for a three-year training programme. Of the many possible deficiencies encountered, these are some of the more common.

The College has now visited all hospitals once and hospitals are now being visited for the second, third or more times. The intention is that standards should progressively rise, but training programmes acceptable at the first visit may not always be approved at more recent visits.

Some consultants do not wish to be involved with training at all. There is nothing to criticize in this, but trainees cannot be attached to these seniors, who will probably work with those in non-training grades.

The category P (Provisional Approval) allows continuing training for one or two years, when there will be another visit to reassess the programme. This category is a warning which should be used by the hospital to insist on being given more resources or modifications of the training programme as indicated by the final recommendations from the Court of Electors. Hospitals in category A (Approved) are now visited again routinely after four years to ensure that teaching standards are maintained. Discussions at present going on may result in an extension to five years.

Special problems derive from some district general hospital psychiatric units with few trainees, which makes for difficulty in organizing meetings for postgraduate education. Some of these units, although doing good clinical work, have relatively limited experience available, especially of subspecialties, and some are at an inconvenient distance from larger psychiatric hospitals to which there might be visits or with which a rotation might be set up. It must be accepted that a few units with these limitations may never be able to arrange adequate training.

Occasionally an Approval team has been actually requested by a tutor to recommend category $\mathbf{P}$ as a means of obtaining much-needed facilities. However, this useful leverage may lately have been losing some of its force because of the economic climate. Some resources, although essentially needed, remain unobtainable because of funding shortage. This seems to be occurring despite the repeated assertion by the DHSS that psychiatric services should be spared cuts relative to the acute general hospital services.

Some problems are not directly related to the standard of teaching. Our College has embarked on an Approval programme which is similar to those organized by the other Royal Colleges, but their programmes are much further forward. We started quite recently, and so a very large number of visits have been necessary. Every hospital had to be visited at first, and frequent revisits made where Provisional categories were allocated on the first occasion. So there have been criticisms by local finance officers of the expenses involved, but the cost surely must be moderate when the Exercise has resulted in very noticeable improvements in the quality of teaching and clinical standards of many psychiatric hospitals and units.
Another difficulty is that the particular needs for postgraduate education of the usual large psychiatric hospitals are not always recognized outside psychiatry. For example, there is an increasing tendency for each Health District to have one clinical tutor who may well not be a psychiatrist even though the District contains a large psychiatric hospital. This hospital may be relatively much more important for training psychiatrists than the local general hospital will be in training those of other specialtir s, and the special resources required for the psychiatric iospital in these circumstances can be difficult to obtain. For example, there may be pressure sometimes to reduce the number of medical libraries as an economy, and therefore to insist that psychiatric books should be placed in the general hospital library. The psychiatric hospital, with a large number of trainees requiring easy access to books, then constitutes a special case with regard to postgraduate training.

Complex administrative problems may be encountered when setting up rotating trainee programmes. Junior doctors may need to be allocated to several different hospitals during training, some administrators find this difficult to organize because of contracts, problems with accommodation, and it may be difficult to obtain the co-operation of the different finance departments involved. The Approval team can help here by their ability to point out similar programmes successfully managed at other hospitals, perhaps in the same Region. Information from colleagues on the Central Panel may help in arguing the case.

There is an increasing and desirable trend for trainees to be taken on for a three-year training period. But again there may be financial problems. These can sometimes be solved by pooling the salaries of the trainees and paying them as an SHO for one or two years and as a registrar for the final year or years. The number of registrars and SHOs in the pool for which finance is available is obviously critical, but some finance officers administer such arrangements more readily than others, and it is a further area where administrators may be helpful or obstructive.

For all that the Approval Exercise has its limitations and may be losing some of its teeth because of economic decline, it has had a very large measure of success and has undoubtedly raised training standards, which must be associated with improved patient care.

I have regarded it as a privilege to have been a Convener. It was a fascinating experience to meet consultant colleagues and to share their battles for finances, to study their styles of organizing training and to admire clinical and teaching work of a high standard carried out sometimes despite poor resources and high case-loads. Although time consuming, I found it to be an extremely rewarding experience and was sorry when my four years in office were completed. I would not have missed it for anything and I can only hope that my stimulating and ever-hospitable colleagues in the NorthEastern Division feel similarly. 